\title{
ARTICLE
}

\section{Human rights in psychiatric practice: an overview for clinicians}

\author{
Brendan D. Kelly
}

\begin{abstract}
Brendan D. Kelly is Associate Clinical Professor of Psychiatry at University College Dublin and a consultant psychiatrist at the Mater Misericordiae University Hospital, Dublin. In addition to his medical degree, he holds doctorates in medicine (MD), history (PhD), governance (DGov) and law (PhD) Correspondence Professor Brendan D. Kelly, Associate Clinical Professor of Psychiatry, Department of Adult Psychiatry, UCD School of Medicine and Medical Science, University College Dublin, Mater Misericordiae University Hospital, 62/63 Eccles Street, Dublin 7, Ireland. Email: brendankelly35@ gmail.com
\end{abstract}

\begin{abstract}
SUMMARY
Matters relating to human rights arise in almost every area of psychiatric practice. Although some statements of rights are non-binding declarations (e.g. the United Nations' Principles for the Protection of Persons with Mental IIIness and the Improvement of Mental Health Care), others are legally binding (e.g. the European Convention on Human Rights) and actively shape national laws. Persons with mental illness commonly experience violations of rights, including their economic and social rights. Psychiatrists can promote human rights through high-quality, evidence-based clinical practice; patient-centred service management; social awareness and engagement; and international activism to enhance protection and promotion of the rights of people with mental illnesses at global level.
\end{abstract}

\section{LEARNING OBJECTIVES}

- Appreciate the background to human rights in psychiatric practice

- Understand key declarations on human rights as they pertain to psychiatry

- Appreciate the ways in which psychiatrists can promote human rights through clinical practice, service management, social engagement and international activism

\section{DECLARATION OF INTEREST}

None

Issues relating to human rights are a staple feature of psychiatric practice. They arise in virtually every area of practice, ranging from involuntary treatment to decisions about deployment of scarce resources, from neglect of the social rights of the mentally ill to reports of active abuses of human rights in institutions in various parts of the world (Bloch 1985; Munro 2002).

This article provides an overview of human rights from the perspective of the practising clinical psychiatrist and outlines ways in which clinicians can protect and promote human rights in day-to-day clinical practice. It commences with an overview of the idea of human rights; summarises key declarations of rights as they relate to psychiatry; and then outlines key ways in which clinicians can promote human rights through clinical practice, service management, social engagement and international activism.

\section{Overview of human rights}

\section{What are human rights?}

A right is an entitlement that one may legally or morally claim. The term 'human rights' refers specifically to rights that a human being possesses by virtue of the fact that he or she is a human being. Human rights do not need to be earned or granted; they are the birthright of all human beings simply because they are human beings; no other qualification is required (Edmunson 2004). The concepts and values underlying human rights have a long history, but today the term 'human rights' is most commonly understood by reference to statements of human rights dating from the 20th century, including, most notably, the Universal Declaration of Human Rights (UDHR) adopted by the United Nations (UN) General Assembly in 1948.

\section{The Universal Declaration of Human Rights}

The UDHR comprises 30 articles, preceded by a short preamble which recognises that 'the inherent dignity and [...] the equal and inalienable rights of all members of the human family is the foundation of freedom, justice and peace in the world' and that 'it is essential, if man is not to be compelled to have recourse, as a last resort, to rebellion against tyranny and oppression, that human rights should be protected by the rule of law' (Preamble). Article 1 of the UDHR states that 'all human beings are born free and equal in dignity and rights' and article 2 establishes the universal nature of these rights:

'Everyone is entitled to all the rights and freedoms set forth in this Declaration, without distinction of any kind, such as race, colour, sex, language, religion, political or other opinion, national or social origin, property, birth or other status.'

This emphasis on universality is both useful and necessary, not least because previous declarations of rights had commonly been interpreted in such a way as to exclude certain groups. The UDHR provides a list of factors that explicitly are not 
to form the basis of discrimination in relation to rights. Although mental illness is not specifically mentioned in this list, the universal spirit of the UDHR is beyond doubt and its exhortation against discrimination on the basis of 'other status' can be reasonably interpreted as including discrimination on the basis of mental illness. In 1991, the UN made this explicit in its Principles for the Protection of Persons with Mental Illness and the Improvement of Mental Health Care, to which I will return later in this article.

Articles 3 to 19 of the UDHR articulate a range of rights fundamentally rooted in the principle of liberty, including 'the right to life, liberty, and security of person' (article 3). The explicit articulation of this right, especially in the context of universal rights, is particularly relevant to people with mental illnesses, not least because of their increased risk of involuntary detention. Again, the need to respect the right to liberty, along with the other rights outlined in the UDHR, was strongly re-emphasised in the UN's 1991 Principles.

Articles 20 to 26 of the UDHR outline rights related to equality and political participation: article 23 provides for the individual's 'right to work'; article 25 states that ' everyone has the right to a standard of living adequate for the health and well-being of himself and of his family, including food, clothing, housing and medical care and necessary social services, and the right to security in the event of unemployment, sickness, disability, widowhood, old age or other lack of livelihood in circumstances beyond his control'; and article 26 provides 'the right to education' which 'shall be free, at least in the elementary and fundamental stages'. Articles 27 and 28 outline social and cultural rights 'to participate in the cultural life of the community, to enjoy the arts and to share in scientific advancement and its benefits' within the context of 'a social and international order in which the rights and freedoms set forth in this Declaration can be fully realized'. Achieving this kind of 'social and international order' has proven a complex task but the UDHR, along with various other international documents, has played a key role in establishing international law as a concept with increasing, positive influence on world affairs (Robertson 2012).

\section{The European Convention on Human Rights}

Despite its many merits and undoubted importance, the UDHR does not have the force of hard law: it is not legally binding, even in ratifying states. By way of contrast, the Convention for the Protection of Human Rights and Fundamental Freedoms (also known as the European Convention on Human Rights or ECHR), adopted by the Council of Europe in 1950, has significantly greater force in law. Like the UDHR, the ECHR aims to protect human rights and fundamental freedoms "which are the foundation of justice and peace in the world and are best maintained on the one hand by an effective political democracy and on the other by a common understanding and observance of the Human Rights upon which they depend' (Preamble).

Also like the UDHR, the EHCR outlines a range of basic individual rights, including rights to life (article 2), liberty, security and a fair trial (articles 5 and 6); respect for private and family life (article 8); freedom of thought, conscience, religion (article 9), expression (article 10), assembly and association (article 11); the right to marry (article 12); and the right to 'an effective remedy before a national authority notwithstanding that the violation has been committed by persons acting in an official capacity' (article 13). There are prohibitions on torture (article 3), slavery, forced labour (article 4) and discrimination (article 14).

Unlike the UDHR, the ECHR established a binding legal mechanism for the enforcement of these rights, the European Court of Human Rights (article 19), which was founded in January 1959. In recent decades, the ECHR was given 'further effect' in the UK with the introduction of the Human Rights Act 1998, which incorporates most of the ECHR, and statute is now expected to be compliant with the Human Rights Act 1998 and ECHR. In Ireland, the ECHR was given 'further effect' with the European Convention on Human Rights Act 2003, albeit that the 2003 Act is 'subject to the Constitution' of Ireland (i.e. if a provision of the 2003 Act conflicts with the Constitution of Ireland, it is the Constitution that takes precedence).

Overall, the six decades since the ECHR was adopted have furnished significant evidence that it has, as intended, provided enhanced protection of human rights (Smith 2007; Rainey 2014) and helped emphasise certain important legal principles, such as the positive obligation of public bodies to take reasonable operational measures to prevent violations of the ECHR (Wadham 2007). Most especially, the ECHR has had significant impact on the field of human rights in psychiatry.

\section{Key elements of human rights as they relate to psychiatry}

\section{The European Convention on Human Rights}

There is now a substantial body of jurisprudence in relation to mental illness and the ECHR, relating chiefly to involuntary detention owing 
a. For example, Winterwerp v Netherlands (1979) 2 EHRR 387; $X$ $\checkmark$ UK (1981) 4 EHRR 188; HL $v$ UK (Bournewood) (2004) 40 EHRR 761.

b. $R$ (Heather) $v$ Leonard Cheshire Foundation [2002] EWCA Civ 366; [2002] 2 All ER 936. See also: Aston Cantlow and Wilmcote with Billesley PCC Church Councilv Wallbank [2003] UKHL 37; [2004] 1 AC 546; and the Health and Social Care Act 2008, section 145.

c. Savage v South Essex Partnership NHS Foundation Trust [2008] UKHL 74; [2010] EWHC 865 (QB).

d. Rabone and Anor v Pennine Care NHS Trust [2012] UKSC 2. See also: Osman v UK (2000) 29 EHRR 245. to mental illness, conditions while detained, and mechanisms for reviews and appeal (Perlin 2006; Bartlett 2007). This reflects the fact that the key provisions of the ECHR in relation to psychiatry concern involuntary detention rather than economic and social rights.

In the first instance, the ECHR states that 'everyone has the right to liberty and security of person. No one shall be deprived of his liberty save in the following cases and in accordance with a procedure prescribed by law', including 'the lawful detention of persons for the prevention of the spreading of infectious diseases, of persons of unsound mind, alcoholics or drug addicts or vagrants' (article 5(1)). In addition:

'Everyone who is deprived of his liberty by arrest or detention shall be entitled to take proceedings by which the lawfulness of his detention shall be decided speedily by a court and his release ordered if the detention is not lawful' (article 5(4)).

These provisions have led to a relatively large number of cases in the European Court of Human Rights clarifying specific matters, ${ }^{a}$ many of which relate to the nature and conditions of detention (Curtice 2008; 2009). These cases and concerns contributed significantly to shaping the Mental Capacity Act 2005 and the 2007 amendments to the Mental Health Act 1983 in England and Wales (Fennell 2007). The Deprivation of Liberty safeguards under the Mental Capacity Act 2005, for example, stemmed directly from the Bournewood case. Other relevant ECHR rights include article 8(1), which specifies that 'everyone has the right to respect for his private and family life, his home and his correspondence'. The issue of patients' 'correspondence' in special hospitals, for example, has been examined by the European Court of Human Rights in the context of this right (Curtice 2009).

One of the most interesting elements of the ECHR, however, is the positive obligation that states appear to be under to protect, as opposed to simply not to violate, ECHR rights. In the UK, the Human Rights Act makes it 'unlawful for a public authority to act in a way which is incompatible with a Convention right' (section 6(1)). Although there has been controversy about what precisely constitutes a 'public authority', it is now reasonably clear that any entity (governmental or private) involved in the delivery of State services is a 'public authority' in respect of those services, including mental health services provided by psychiatrists and others. ${ }^{\text {b }}$ There is a similar (although not identical) provision in Ireland, where the European Convention on Human Rights Act 2003 states that, 'subject to any statutory provision (other than this
Act) or rule of law, every organ of the State shall perform its functions in a manner compatible with the State's obligations under the Convention provisions' (section 3). These provisions appear to place substantial and arguably unfulfillable positive obligations on public authorities such as mental health services to protect ECHR rights including, for example, protecting the right to life by preventing suicide (Rahman 2013).

More specifically, the case of Savage ${ }^{\mathrm{c}}$ in 2010 involved the suicide of a detained psychiatric patient and it was alleged that the relevant National Health Service (NHS) trust had failed to protect the patient's ECHR right to life (article 2(1)). The House of Lords concluded that the NHS trust had a duty to reasonably protect psychiatric patients from taking their own lives, under the Human Rights Act 1998. In 2012, the Supreme Court concluded in another case ${ }^{\mathrm{d}}$ that the NHS trust concerned had breached its duty of care to a voluntary psychiatric in-patient who died by suicide while on leave home from a psychiatric unit. These cases, which are discussed in more detail in a fascinating paper by Rahman $\mathcal{E}$ Wolferstan (2013), demonstrate the very substantial extent of the positive obligation to protect the right to life by preventing suicide that appears to stem from the ECHR and Human Rights Act 1998. It is difficult, if not impossible, to see how this obligation can be fulfilled in day-to-day clinical practice.

\section{UN Principles for the Protection of Persons with Mental IIIness and the Improvement of Mental Health Care}

The UDHR and ECHR are general declarations of human rights. The most detailed declaration of rights in the specific context of mental illness is provided by the UN in its Principles for the Protection of Persons with Mental Illness and the Improvement of Mental Health Care (UN 1991). These are summarised in Box 1 and emphasise that all people are entitled to receive the best mental healthcare available, be treated with humanity and respect, and receive mental healthcare based on internationally accepted ethical standards. In addition, mental health facilities shall be appropriately structured and resourced, and an impartial review body shall, in consultation with mental health practitioners, review the cases of involuntary patients.

Many of these principles were re-emphasised in 1996 in the World Health Organization's (WHO's) Ten Basic Principles of Mental Health Care Law (WHO Division of Mental Health and Prevention of Substance Abuse 1996) (Box 2), which state that 'decisions should be made in keeping with the 
body of law in force in the jurisdiction involved and not on another basis nor on an arbitrary basis'.

Against this background, the WHO published the most detailed systematic set of human rights standards for national mental health legislation assembled to date, in its Resource Book on Mental Health, Human Rights and Legislation (WHO 2005). In this, the WHO sets out a 'checklist for mental health legislation' detailing specific human rights standards which, according to the WHO, need to be met in each jurisdiction. These standards are clearly based on previous UN and WHO publications and centre on the provision of mental healthcare that is reasonable, equitable and in accordance with international standards. Mental health legislation in each jurisdiction has a key role in meeting these WHO standards: in England and Wales, civil mental health legislation meets $90(54.2 \%)$ of the 166 relevant standards, while legislation in Ireland meets 80 (48.2\%) (Kelly 2011). Areas of relatively high compliance include definitions of mental disorder, procedures for involuntary admission and treatment, and clarity regarding offences and penalties. Areas of medium compliance relate to competence, capacity and consent; oversight and review (which exclude long-term voluntary patients); and rules governing special treatments, seclusion and restraint. Areas of low compliance relate to promoting rights, voluntary patients (especially non-protesting, incapacitous patients), protection of vulnerable groups and emergency treatment.

\section{The UN Convention on the Rights of Persons with Disabilities}

In 2006, the human rights landscape again changed significantly with the adoption of the Convention on the Rights of Persons with Disabilities (CRPD) by the UN General Assembly (Bartlett 2007). The CRPD commits signatory countries 'to promote, protect and ensure the full and equal enjoyment of all human rights and fundamental freedoms by all persons with disabilities, and to promote respect for their inherent dignity' (article 1). It specifies that 'persons with disabilities include those who have long-term physical, mental, intellectual or sensory impairments which in interaction with various barriers may hinder their full and effective participation in society on an equal basis with others' (article 1).

The UK signed the CRPD in 2007 and ratified it in 2009; Ireland also signed it in 2007 but has yet to ratify it. Ratification means that a state indicates its consent to be bound by the CRPD and this is monitored by the Committee on the Rights of Persons with Disabilities.

BOX 1 Summary of key UN Principles for the Protection of Persons with Mental IIIness and the Improvement of Mental Health Care

- All people are entitled to receive the best mental healthcare available and to be treated with humanity and respect

- There shall be no discrimination on the grounds of mental illness: all people with mental illnesses have the same rights to medical and social care as other ill people

- All people with mental illnesses have the right to live, work and receive treatment in the community, as far as possible

- Mental healthcare shall be based on internationally accepted ethical standards, and not on political, religious or cultural factors

- The treatment plan shall be reviewed regularly with the patient

- Mental health skills and knowledge shall not be misused

- Medication shall meet the patient's health needs and shall not be administered for the convenience of others or as a punishment
- In the case of voluntary patients, no treatment shall be administered without their informed consent, subject to some exceptions (e.g. patients with personal representatives empowered by law to provide consent); in the case of involuntary patients, every effort shall be made to inform the patient about treatment

- Physical restraint or involuntary seclusion shall be used only in accordance with official guidelines

- Records shall be kept of all treatments

- Mental health facilities shall be appropriately structured and resourced

- An impartial review body shall, in consultation with mental health practitioners, review the cases of involuntary patients

(Adapted from: UN 1991)

In the context of psychiatry, it seems clear that the CRPD's definition of 'persons with disabilities' does not include all people with mental disorder,

\section{B0X 2 Descriptions of World Health Organization's Ten Basic Principles} of Mental Health Care Law

1 Everyone should benefit from the best possible measures to promote their mental well-being and to prevent mental disorders.

2 Everyone in need should have access to basic mental health care.

3 Mental health assessments should be made in accordance with internationally accepted medical principles and instruments (e.g: WHO's ICD-10 Classification of Mental and Behavioural Disorders - Clinical Descriptions and Diagnostic Guidelines, Tenth revision, 1992).

4 Persons with mental health disorders should be provided with health care which is the least restrictive.

5 Consent is required before any type of interference with a person can occur.

6 In case a patient merely experiences difficulties in appreciating the implications of a decision, although not unable to decide, he/she shall benefit from the assistance of a knowledgeable third party of his or her choice.

7 There should be a review procedure available for any decision made by official (judge) or surrogate (representative, e.g. guardian) decisionmakers and by health care providers.

8 In the case of a decision affecting integrity (treatment) and/or liberty (hospitalization) with a long-lasting impact, there should be an automatic periodical review mechanism.

9 Decision-makers acting in official capacity (e.g. judge) or surrogate (consent-giving) capacity (e.g. relative, friend, guardian) shall be qualified to do so.

10 Decisions should be made in keeping with the body of law in force in the jurisdiction involved and not on another basis nor on an arbitrary basis.

(Reproduced, with the permission of the publisher, from WHO Division of Mental Health and Prevention of Substance Abuse 1996) 
not least because many mental disorders (e.g. adjustment disorder) are not 'long-term' (Kelly 2014a). The CRPD does not, however, present its definition of 'persons with disabilities' as a comprehensive one, but states that the term 'persons with disabilities' includes people with long-term impairments; others, presumably, may also fit the definition. As a result, it is likely that some people with mental disorder meet the definition at least some of the time (e.g. an individual with an intellectual disability) whereas others do not (e.g. an individual with adjustment disorder). Moreover, the CRPD states that 'disability is an evolving concept and [that it] results from the interaction between persons with impairments and attitudinal and environmental barriers that hinders their full and effective participation in society on an equal basis with others' (Preamble); this unlinks the definition of 'persons with disabilities' from any specific diagnoses and moves it into a social context.

\section{Legislative violations of the CRPD}

Both mental health legislation and mental capacity legislation in various jurisdictions appear to violate the CRPD. For example, the CRPD specifies that 'the existence of a disability shall in no case justify a deprivation of liberty' (article 14(1)). If certain persons with mental disorder (e.g. some people with chronic schizophrenia) fit the UN definition of 'persons with disabilities', then mental health legislation in England, Wales and Ireland (for example) is clearly inconsistent with this provision, given the clear links that legislation makes between mental disorder, risk and involuntary admission (Kelly 2014a).

In relation to legal capacity, the CRPD specifies that persons with disabilities 'enjoy legal capacity on an equal basis with others in all aspects of life' (article 12(2)) and this appears to be violated by the fact that the remit of decision-making supports is limited in several jurisdictions; e.g. Ireland's draft Assisted Decision-Making (Capacity) Bill 2013 excludes areas such as marriage and voting from its decision-making supports (section 106) (Kelly 2014b); in the Mental Capacity Act 2005 governing England and Wales, family relationships (section 27), Mental Health Act matters (section 28) and voting rights (section 29) are excluded; while in Northern Ireland, the draft Mental Capacity Bill 2014 has exclusions for family relationships (section 149) and voting rights (section 150). In addition, it is not at all clear whether or not the CRPD is consistent with any form of substitute decision-making, although there is some evidence that it may be deemed acceptable in certain circumstances (Bartlett 2012; Szmukler 2014).
Minkowitz (2007), a chairperson of the World Network of Users and Survivors of Psychiatry and member of the UN working group that produced the first draft of the CRPD, argues that all forced psychiatric interventions are by their very nature violations of the CRPD, requiring that perpetrators (i.e. mental health professionals) be criminalised and victims receive reparations. Minkowitz bases this argument on alleged violations of CRPD articles 12 ('equal recognition before the law'), 15 ('freedom from torture or cruel, inhuman or degrading treatment or punishment'), 17 ('protecting the integrity of the person') and 25 ('health', especially the requirement for 'free and informed consent' to care). Current mental health legislation may also violate article 4(1) (no 'discrimination of any kind on the basis of disability') (Szmukler 2014). In the UK jurisdictions and Ireland, however, there are national laws permitting involuntary psychiatric detention and treatment under certain circumstances and, if such laws are observed, it appears unlikely that mental health professionals can be labelled as criminals.

\section{Promoting human rights in psychiatry}

In light of these various declarations of rights and related case law, how can practising psychiatrists and other mental health professionals best protect and promote the human rights of persons with mental disorder? Clearly, the first step is to become familiar with the human rights frameworks of the ECHR, WHO, UN and CRPD, in terms of both their specific provisions and the values they seek to promote. Familiarity with national mental health legislation is clearly a key part of this, but observance of rights stretches well beyond legislative measures, and Box 3 presents five free online resources relating to the broader promotion of the rights of the mentally ill. Box 4 lists five key books relating to human rights and psychiatry, viewed, again, in these broader social contexts.

\section{The concept of dignity}

In terms of day-to-day clinical practice, it is clear that observance of the values outlined in the UDHR, ECHR and CRPD requires a dynamic balance between support and autonomy, and that this balance may vary over time, especially (but not exclusively) among persons with mental disorder (Minkowitz 2010). To help operationalise these concepts in clinical practice, it is useful to note that the concept of dignity is central to all rights and there is arguably no human right that is not connected with dignity (Feldman 2002; Osiatynski 2009). This emphasis on dignity is consistent with 
the emphasis that the preambles of the UDHR and CRPD both place on the 'inherent dignity' of all persons, and provides a good principle to guide the promotion of human rights in psychiatric practice (Kelly 2014c). Dignity was also a key theme running through the Mid Staffordshire NHS Foundation Trust Public Inquiry (2013) and featured in its final recommendations

But what exactly is dignity? And how can the concept of dignity be used to promote rights in mental health settings, especially when the person in question may lack insight into their situation and temporarily lack the capability to exercise their own rights or promote their own dignity in certain important respects? For example, an individual with schizophrenia who is untreated, homeless and shouting at passers-by on the street is, by most objective standards, in an undignified position, but may not perceive this indignity subjectively, owing to the effects of illness. An individual without schizophrenia in a similar position is more likely to perceive their situation differently, experience subjective indignity and take remedial action. How can approaches based on human rights and dignity assist in this situation?

As a starting point, it is useful to recognise that dignity has both subjective and objective dimensions, and there is a dynamic interplay between the two (Beyleveld 2001; Feldman 2002). A pragmatic approach to operationalising these concepts in clinical settings is provided by Seedhouse \& Gallagher (2002), who propose that a person has dignity when they are in a situation in which their capabilities can be applied. In other words, there are two key elements in establishing dignity: capabilities and circumstances. On this basis, if a mental health worker seeks to support

BOX 3 Five free online resources relating to human rights and psychiatry

Human Rights in Mental Health Federation Global Initiative on Psychiatry An international federation of not-for-profit organisations founded in 1980 as the International Association on the Political Use of Psychiatry. It actively supports the development of mental health services in low- and middle-income countries and seeks to bring about structural reforms by working at both grass-roots and governmental level. The website is an excellent resource for clinicians interested in human rights in psychiatry, providing a guide to the federation's activities, access to publications and reports, and much more.

www.gip-global.org

\section{WHO Resource Book on Mental Health,} Human Rights and Legislation

The most detailed set of human rights standards for mental health legislation published to date and includes a Checklist for Mental Health Legislation, detailing specific human rights standards that, according to the WHO, need to be met in each jurisdiction. www.who.int/mental_health/policy/ legislation/essentialpackage2v1/en

WHO mental health portal

Access to a wealth of WHO resources relating to mental health policy, mental health in emergencies and, in particular, the WHO Mental Health Gap Action Programme (mhGAP), which aims at scaling up services for mental, neurological and substance use disorders, especially in low- and middleincome countries.

www.who.int/mental_health/en

\section{United Nations Enable}

The official website of the UN Secretariat for the Convention on the Rights of Persons with Disabilities (SCRPD). Provides public information on topics related to disability, updates on the work of the UN for persons with disabilities, and a wealth of information about the CRPD, including its full text, dates of signature and ratification by various countries, and myriad other resources.

www.un.org/disabilities

\section{Royal College of Psychiatrists' Special} Committee on Human Rights

This site provides details of the committee's membership, a brief history, a statement of principles and purpose, and links to relevant legislation, articles and an especially useful guide to the UK legal system.

www.rcpsych.ac.uk/workinpsychiatry/ specialcommitteesofcouncil/humanrights.

aspx

BOX 4 Five key books relating to human rights and psychiatry

Bartlett P, Lewis 0, Thorold 0 (2007) Mental Disability and the European Convention on Human Rights. Martinus Nijhoff Publishers.

Bartlett P, Sandland R (2014) Mental Health Law: Policy and Practice (4th edn). Oxford University Press.

Dudley M, Silove D, Gale F (eds) (2012) Mental Health and Human Rights: Vision, Praxis, and Courage. Oxford University Press

Gostin L, Bartlett P, Fennell P, McHale J, Mackay RD (2010) Principles of Mental Health Law and Policy. Oxford University Press.

McSherry B, Weller P (eds) (2010) Rethinking Rights-Based Mental Health Laws. Hart Publishing.
Focuses on the ECHR and related case law in the context of mental disability, but is also a valuable example of lucid thinking about rights, in the context not only of healthcare but also of broader community participation. As a result, many of the discussions in the book are of increasing relevance as experience with the CRPD grows.

A superb guide to mental health law in practice, with plenty of reference to recent cases and new legislation, especially in England and Wales. Many of its discussions and conclusions have broad international applicability.

This interesting, diverse volume includes contributions on culture and context in human rights, the relevance of genes and biology, political abuses of psychiatry, the pharmaceutical industry, vulnerable groups, rights in poorly resourced settings, and the challenges of global mental health and human rights. A detailed and important book, not least because the authors clearly recognise the links between mental health law and policy which together shape mental health services and, in significant part, the observance or denial of rights among people with mental illnesses.

A series of provocative and thoughtful essays on human rights and mental health law from a range of international perspectives. It includes contributions on the limits of rights-based approaches, the CRPD, compulsory out-patient treatment and human rights outside the 'first world'. 
mental health service management, broader social engagement and international activism.

\section{Human rights in clinical practice}

The key way in which psychiatrists can promote human rights in clinical settings is by providing high-quality, evidence-based mental healthcare that reduces patients' symptoms, increases capabilities, enhances dignity and thus promotes rights. There is strong evidence that medications commonly used in psychiatry are as effective as those used in general medicine (Leucht 2012) and there are growing, convincing evidence bases for various psychological therapies (Gabbard 2007). Using these therapies wisely, judiciously and as indicated makes a strong contribution to enhancing individual agency and promoting rights.

That is not to say that routine clinical practice is necessarily sufficient in itself to promote rights, but rather that providing care that is evidencebased and effective is probably the most important contribution psychiatrists routinely make to increasing dignity and enjoyment of rights, and it is a vital contribution. Familiarity with national mental health legislation is a key element of this, and there are excellent guides available for the Mental Capacity Act 2005 (Brindle 2013) and Mental Health Act 1983 (Zigmond 2014), for example, to assist with this work. Multidisciplinary team-work is also critical, recognising that recovery depends on diverse inputs that address social needs as well as psychological and medical ones (Gabbard 2001). All of these measures in and of themselves help protect patients' rights in important and enduring ways.

\section{Human rights and service management}

Psychiatrists are commonly involved in shaping specific aspects of the management of mental health services and these are key determinants of the circumstances in which patients experience and construct their recoveries. These circumstances also play an important role in the promotion or undermining of dignity, and Shotton $\&$ Seedhouse (1998) directly link loss of dignity to the extent to which circumstances prevent exercise of capabilities. In this context they articulate various levels of loss of dignity, including trivial loss (when dignity is easily restored), serious loss (when substantial effort is required to restore dignity) and devastating loss (when it is impossible to regain dignity without help). An awareness of these possibilities can usefully inform involvement in service planning and delivery.

More specifically, creating appropriate circumstances to support dignity involves developing an awareness of the importance of respect, weighing the balance between independence and dependence, and promoting the individual's own priorities and interests, in the context of staff practices, clinical environments, healthcare resources and various other aspects of organising care (Gallagher 2002). For psychiatrists, it is important that involvement in service management promotes improved circumstances for patients by developing mental health facilities of an adequate standard; implementing staffing practices that recognise patient concerns as well as staff requirements; and ensuring patient involvement in service development.

\section{Human rights and social engagement}

Mental illness and recovery are experienced in specific social contexts and these circumstances invariably play important roles in recovery and reintegration following episodes of mental disorder. Poor people are likely to develop mental disorders at earlier ages and have longer durations of untreated illness, and anyone with a mental disorder is at greater risk of underemployment and homelessness, and more likely to be arrested in similar circumstances than someone without such a disorder (Kelly 2005, 2006). These adverse societal factors, combined with the stigma of mental illness, constitute a form of 'structural violence' that amplifies the effects of mental disorders in the lives of sufferers and their families, and effectively excludes many from full participation in civic and social life.

Against this background, there is a clear role for psychiatry in social advocacy for the mentally ill. The CRPD is of great assistance in this regard, owing to its welcome articulation of the rights of persons with disabilities in the broader social context, rather than just in the context of healthcare. The CRPD is thus a powerful tool with which to advocate for better, more equitable treatment of people with mental disorder not just in healthcare settings, but also in terms of social care, as well as broader acceptance and genuine integration in society. A growing awareness of the importance of public mental health is another welcome recognition of the importance of contextual factors in recovery from mental disorder and maintaining mental wellness (Eaton 2012). There are clear, compelling roles for psychiatrists in these areas, especially in relation to social advocacy for our patients.

\section{Human rights and international activism}

Global health inequality is easily the greatest single bioethical issue of our times, and this is as true in mental health as it is in other areas 
of medicine. The WHO (2014) points out that although $14 \%$ of the global burden of disease is attributable to mental, neurological and substance use disorders, most of the people affected (up to $75 \%$ in many low-income countries) do not have access to the treatment they need. This is a truly global problem, and while the human rights issues that face persons with mental disorder in high-income countries (commonly relating to involuntary admission and treatment) certainly merit attention and remedy, the greatest human rights issue at global level is lack of access to care, rather than protection from it.

In this context, issues of discrimination, exclusion from care, denial of agency and lack of social security are key factors in determining the kinds of lives that persons with mental disorder actually lead (Kelly 2005; Callard 2012). An international perspective is essential if psychiatrists are to appreciate the nature and extent of these challenges, and seek possible solutions. In the area of mental health law, for example, there are interesting and contrasting developments in various jurisdictions: in Ireland, it was recently proposed that 'dignity' should become the overarching principle of mental health legislation (Kelly 2014c), whereas in Northern Ireland, the draft Mental Capacity Bill 2014 suggests merging mental health and capacity legislation into a single act, thus increasing compliance with the CRPD but also, intriguingly, retaining 'best interests' as the overarching principle, in apparent violation of the CRPD. These diverse approaches merit study.

There are equally interesting developments elsewhere around the world, and Callard and colleagues (2012) provide valuable examples of initiatives and practices in countries such as New Zealand, India and Indonesia. An awareness of this global dimension to human rights in mental health can both stimulate global activism at transnational level and enhance advocacy and protection of rights at local or national level. The resources in Box 3 indicate ways to get involved.

An awareness of the global context of human rights in mental health also highlights that, while protecting the right to liberty is a crucial first step, there are many other rights too, most of which are substantially shaped by social, economic and political realities. All of these issues require solutions based not just in the clinic, but in the arenas of political advocacy, economic reform and campaigns for global social justice. Aux barricades!

\section{References}

Bartlett P, Lewis 0, Thorold 0 (2007) Mental Disability and the European Convention on Human Rights. Martinus Nijhoff Publishers.
Bartlett P (2012) The United Nations Convention on the Rights of Persons with Disabilities and mental health law. Modern Law Review, 75: 752-78.

Beyleveld D, Brownsword R (2001) Human Dignity in Bioethics and Biolaw. Oxford University Press.

Bloch S, Reddaway P (1985) Soviet Psychiatric Abuse: The Shadow Over World Psychiatry. Westview Press.

Brindle N, Branton T, Stansfield A, et al (2013) A Clinician's Brief Guide to the Mental Capacity Act. RCPsych Publications.

Callard F, Sartorius N, Arboleda-Flórez J, et al (2012) Mental IIIness, Discrimination and the Law: Fighting for Social Justice. Wiley-Blackwell.

Curtice M (2008) Article 3 of the Human Rights Act 1998: implications for clinical practice. Advances in Psychiatric Treatment, 14: 389-97.

Curtice M (2009) Article 8 of the Human Rights Act 1998: implications for clinical practice. Advances in Psychiatric Treatment, 15: 23-31.

Eaton WW (ed) (2012) Public Mental Health. Oxford University Press.

Edmundson W (2004) An Introduction to Rights. Cambridge University Press.

Feldman D (2002) Civil Liberties and Human Rights in England and Wales (2nd edn). Oxford University Press.

Fennell P (2007) Mental Health: The New Law. Jordans.

Gabbard G0, Kay J (2001) The fate of integrated treatment: whatever happened to the biopsychosocial psychiatrist? American Journal of Psychiatry, 158: 1956-63.

Gabbard G0, Beck JS, Holmes J (eds) (2007) Oxford Textbook of Psychotherapy. Oxford University Press

Gallagher A, Seedhouse D (2002) Dignity in care: the views of patients and relatives. Nursing Times, 98: 38-40.

Kelly BD (2005) Structural violence and schizophrenia. Social Science and Medicine, 61: 721-30.

Kelly BD (2006) The power gap: freedom, power and mental illness. Social Science and Medicine, 63: 2118-28.

Kelly BD (2011) Mental health legislation and human rights in England, Wales and the Republic of Ireland. International Journal of Law and Psychiatry, 34: 439-54.

Kelly BD (2014a) An end to psychiatric detention? Implications of the United Nations Convention on the Rights of Persons with Disabilities. British Journal of Psychiatry, 204: 174-5.

Kelly BD (2014b) The Assisted Decision-Making (Capacity) Bill 2013: content, commentary, controversy. Irish Journal of Medical Science, Mar 12 [Epub ahead of print].

Kelly BD (2014c) Dignity, human rights and the limits of mental health legislation. Irish Journal of Psychological Medicine, 31: 75-81.

Leucht S, Hierl S, Kissling W, et al (2012) Putting the efficacy of psychiatric and general medicine medication into perspective: review of meta-analyses. British Journal of Psychiatry, 200: 97-106.

Mid Staffordshire NHS Foundation Trust Public Inquiry (2013) Report of the Mid Staffordshire NHS Foundation Trust Public Inquiry. TSO (The Stationery Office)

Minkowitz T (2007) The United Nations Convention on the Rights of Persons with Disabilities and the right to be free from non-consensual psychiatric interventions. Syracuse Journal of International Law and Commerce, 34: 405-28.

Minkowitz T (2010) Abolishing mental health laws to comply with the Convention on the Rights of Persons with Disabilities. In Rethinking Rights-Based Mental Health Laws (eds B McSherry, P Weller): 151-77. Hart Publishing.

Munro R (2002) Dangerous Minds: Political Psychiatry in China Today and Its Origins in the Mao Era. Human Rights Watch \& Geneva Initiative on Psychiatry.

Osiatynski W (2009) Human Rights and Their Limits. Cambridge University Press.

Perlin ML, Kanter AS, Treuthart MP, et al (2006) International Human Rights and Comparative Mental Disability Law. Carolina Academic Press.

\section{MCO answers \\ $1 \mathrm{a} \quad 2$ e $\quad 3$ b $\quad 4 d \quad 5 c$}


Rahman MS, Wolferstan N (2013) A human right to be detained? Mental healthcare after 'Savage' and 'Rabone'. Psychiatrist, 37: 294-6.

Rainey B, Wicks E, Ovey C (2014) Jacobs, White \& Ovey: The European Convention on Human Rights (6th edn). Oxford University Press.

Robertson G (2012) Crimes Against Humanity: The Struggle for Global Justice (4th edn). Penguin.

Seedhouse D, Gallagher A (2002) Clinical ethics: undignifying institutions. Journal of Medical Ethics, 28: 368-72.

Shotton L, Seedhouse D (1998) Practical dignity in caring. Nursing Ethics, 5: 246-55.

Smith RKM (2007) Textbook on International Human Rights (3rd edn). Oxford University Press.

Szmukler G, Daw R, Callard F (2014) Mental health law and the UN Convention on the Rights of Persons with Disabilities. International Journal of Law and Psychiatry, 37: 245-52.
United Nations (1991) Principles for the Protection of Persons with Mental IIIness and the Improvement of Mental Health Care. In The Protection of Persons with Mental IIIness and the Improvement of Mental Health Care. United Nations Secretariat Centre For Human Rights.

Wadham J, Mountfield H, Edmundson A, et al (2007) Blackstone's Guide to The Human Rights Act 1998 (4th edn). Oxford University Press.

World Health Organization (2005) WHO Resource Book on Mental Health, Human Rights and Legislation. WHO.

World Health Organization (2014) WHO Mental Health Gap Action Programme (mhGAP). WHO (http://www.who.int/mental_health/mhgap/ en). Accessed 3 Nov 2014

World Health Organization Division of Mental Health and Prevention of Substance Abuse (1996) Mental Health Care Law: Ten Basic Principles. World Health Organization.

Zigmond T (2014) A Clinician's Brief Guide to the Mental Health Act (3rd edn). RCPsych Publications

\section{MCQs}

Select the single best option for each question stem

1 Key rights in the UN's Principles for the Protection of Persons with Mental IIIness and the Improvement of Mental Health Care include:

a all people are entitled to receive the best mental healthcare available and to be treated with humanity and respect

b discrimination on the grounds of mental illness is acceptable in certain situations

c mental healthcare shall be based on political, religious and cultural factors

d mental health facilities shall be located exclusively in rural areas, wherever possible

e an impartial review body shall, without consultation with mental health practitioners, review the cases of involuntary patients.

2 The European Convention on Human Rights was signed in 1950 by:

a the European Union b the European Coal and Steel Community

c the United Nations

d the World Health Organization

e the Council of Europe.

3 The WHO's Ten Basic Principles of Mental Health Care Law include:

a mental health assessments need not be made in accordance with internationally accepted instruments

b everyone should benefit from the best possible measures to promote their mental well-being and to prevent mental disorders

c persons with mental disorders should be provided with healthcare that is as restrictive as feasible

d the patient has no right to the support of a third party in appreciating the implications of a decision

e decisions relating to mental healthcare do not necessarily need to accord with the body of law in force in the jurisdiction involved.
4 The UN Convention on the Rights of Persons with Disabilities:

$a$ is overseen by the European Court of Human Rights

b has the force of domestic law in the UK and Ireland

c emerged initially from the Council of Europe

$\mathrm{d}$ is an international human rights declaration adopted in 2006

e has little or no relevance for clinical psychiatry.

5 Psychiatrists can promote human rights in clinical practice by:

a disengaging from legislative provisions regarding mental healthcare

b focusing only on in-patient care

c delivering evidence-based mental healthcare

d leaving consideration of the social context of mental disorder to other people

e framing human rights issues in national rather than international contexts. 